\title{
Can the Expandable Esophageal Metal Endocoil Stent Be Safely Removed?
}

Metallic self-expanding stents were introduced into the management of malignant esophageal strictures with the aim of improving the quality of palliation and reducing the trauma and morbidity relating to the placement of traditional tubes. Although encoura- ging results were reported in several series $(1,2)$, some drawbacks have also been reported with each of the different self-expanding esophageal stents currently available $(3,4)$. Among the different models now available, the Endocoil stent (Instent Inc., Israel, and 
$\mathrm{a}, \mathrm{b}$

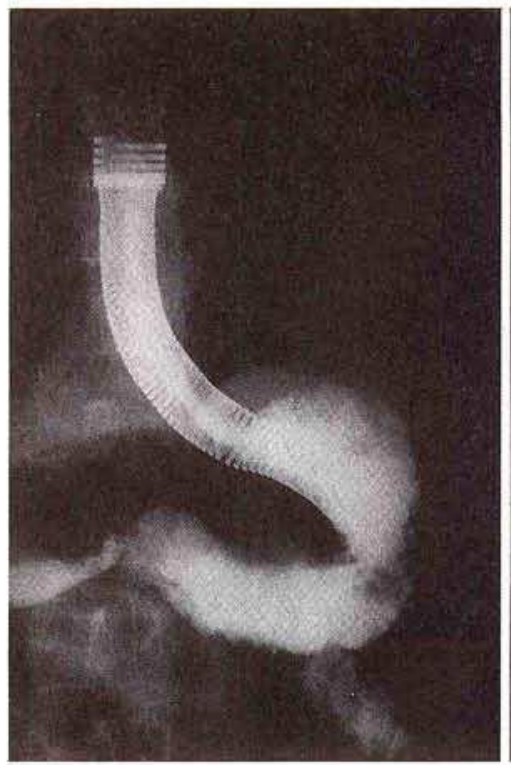

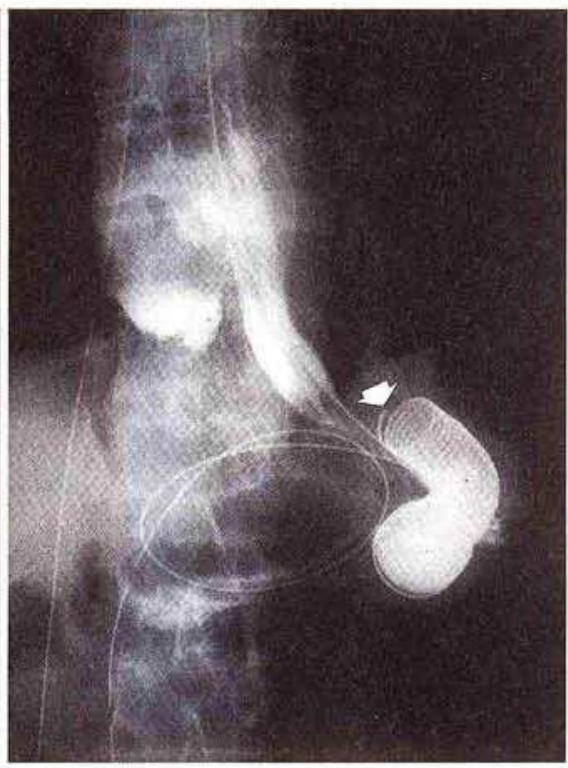

Figure 1: a The Endocoil stent in place, with the distal part in the stomach. $\mathbf{b}$ After the stent migrated into the stomach three months after positioning, an attempt to endoscopic removal was made. The esophagogram with water-soluble contrast shows a full-thickness perforation o the thoracic esophagus caused by the broken edge of the stent (white arrow) returning back into the stomach.

Eden Prairie, Minnesota, USA), consisting of a single flat wire of nickel-titanium alloy, has a coil structure designed to prevent tumor ingrowth, which should theoretically allow endoscopic removal. We report here on a patient with cardia cancer in whom an Endocoil stent became dislodged in the stomach three months after positioning.

During endoscopic removal of the stent, using a pediatric endoscope with an oral overtube and under radiological assistance, the flat wire broke down inside the esophagus when almost half of the prosthesis had already been pulled out from the patient's mouth. The distal broken edge returned roughly inside the stomach, causing a perforation of the lower thoracic esophagus $10 \mathrm{~cm}$ above the cardia tumor (Figure 1). A chest tube was positioned under local anesthesia, and a percutaneous endoscopic gastrostomy was performed to drain the stomach and pass a jejunal feeding tube distal to the ligament of Treitz. During the same endoscopic procedure, a double-lumen nasoesophageal Salem tube was placed at the level of the esophageal perforation. Although total parenteral nutrition, $\mathrm{H}_{2}$-blockers and antibiotics were immediately started, the patient died 30 days after the procedure.

At present, only a few published reports are available on the removal of the Endocoil stent. Goldin et al., in their initial experience in four patients in whom an Endocoil stent had been positioned, reported one distal migration. Stent dislodgment occurred three months after the procedure, but endoscopic removal was easy (5). The authors did not report any corrosion in the removed stent. However, the present case suggests that the mechanical properties of the stent may be significantly impaired when the device remains in contact with acid gastric secretion for some months. Another possibility is that there may have been a weakness in the wire, causing it to fracture under tension. However, the force being used to remove the stent was low, and the rupture occurred suddenly while the flat wire was being progressively withdrawn. In addition, the hypothesis that the breakdown might be related to prolonged acid exposure is also supported by some signs of corrosion in the retrieved stent, close to the point at which the rupture occurred (Figure 2). Since this complication entails a high risk of perforation of the thoracic esophagus, which

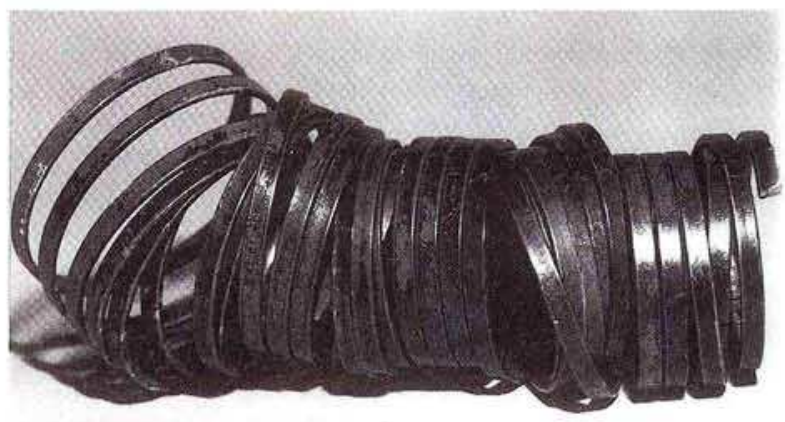

Figure 2: Signs of corrosion are evident in the retrieved stent close to th point at which the rupture occurred.

is usually lethal in patients with advanced esophageal cance surgical removal should be considered.

A. Segalin, L. Bonavina, C. Siardi, A. Carazzone, A. Peracchia Dept. of General and Oncological Surgery, University of Milan, Milan, Italy

\section{References}

1. Ellul JPM, Watkinson A, Khan RJK, Adam A, Mason RC Self-expanding metal stents for the palliation of dysphagia du to inoperable oesophageal carcinoma. Br J Surg 1995; 82 $1678-81$

2. Raijman I, Walden D, Kortan P, Haber GB, Fuchs E, Siemen $\mathrm{M}$, et al. Expandable esophageal stents: initial experience wit a new nitinol stent. Gastrointest Endosc 1994; 40: 614-21.

3. Neuhaus H, Hoffmann W, Dittler HJ, Niedermeyer HP, Classe M. Implantation of self-expanding esophageal metal stents $\mathrm{fc}$ palliation of malignant dysphagia. Endoscopy 1992; 24: 405 10. 
4. Wu WC, Katon RM, Saxon RR, Barton RE, Uchida BT, Keller FS, et al. Silicone-covered self-expanding metallic stents for palliation of malignant esophageal obstruction and esophagorespiratory fistulas: experience in 32 patients and review of the literature. Gastrointest Endosc 1994; 40: 22-33.

5. Goldin E, Beyar M, Safra T, Globerman O, Craciun 1, Wengrower $\mathrm{D}$, et al. A new self-expandable, nickel-titanium coil stent for esophageal obstruction: a preliminary report. Gastrointest Endosc 1994; 40: 64-8.
Corresponding Author

A. Segalin, M.D.

Ospedale Maggiore

Padiglione Monteggia

Via Francesco Sforza 35

Milan

Italy

Fax: $+39-2-55194882$ 